\section{NEW TEMPORARY ATRIAL AND VENTRICULAR PACING LEADS FOR PATIENTS AFTER CARDIAC OPERATIONS}

We have studied two new temporary pacing leads Medtronic 6491 and 6492) intended for pacing after cardiac operations. The conductor has stainless steel strands coated with polyethylene connected to a $4 \mathrm{~mm}^{2}$ surface area, stainless steel, smooth, tapered electrode. A soft 4-0 coiled polypropylene fiber served as a fixation mechanism in the heart. The study included 15 children (aged 3 months to 7 years, body weight 4.4 to $20 \mathrm{~kg}$ ) with a variety of congenital heart defects and 15 adults (aged 45 to 78 years) with coronary artery disease $(n=13)$ and aortic valve disease $(n=2)$. A pair of leads each was placed in a bipolar fashion in the right atrial wall and nonsystemic ventricle in the children (median implant duration 12 days) and in the right atrial wall only in the adults (median implant duration 9 days). The atrial current threshold values in children increased from $0.61 \pm 0.34 \mathrm{~mA}$ immediately after implant to $2.08 \pm 1.86 \mathrm{~mA}$ at explant $(p<0.002)$. In the adults the threshold values increased from $0.95 \pm 1.44 \mathrm{~mA}$ immediately after implant to $2.76 \pm 2.76 \mathrm{~mA}$ at explant $(p$ $<0.002$ ). In the ventricle the threshold values increased from $0.38 \pm 0.13$ $\mathrm{mA}$ immediately after implant to $2.22 \pm 1.63 \mathrm{~mA}$ at explant $(p<0.002)$. Tissue resistance immediately after implant measured $809 \pm 182 \Omega$ in the atrium and increased to $820 \pm 204 \Omega$ at explant (children, $p=$ not significant). Corresponding values in adults were $778 \pm 190 \Omega$ and $599 \pm$ $91 \Omega(p<0.004)$. In the ventricle resistances changed from $1019 \pm 143 \Omega$ to $876 \pm 137 \Omega(p<0.05)$. P wave amplitudes measured $1.8 \pm 1.5 \mathrm{mV}$ immediately after implant and decreased to $1.6 \pm 1.2 \mathrm{mV}$ at explant $(p=$ not significant, children) and $2.0 \pm 1.3 \mathrm{mV}$ to $1.8 \pm 1.1 \mathrm{mV}(p=\operatorname{not}$ significant, adults). $R$ wave amplitudes were $13.1 \pm 3.0 \mathrm{mV}$ immediately after implant and fell to $8.7 \pm 4.5 \mathrm{mV}$ at explant $(p<0.005)$. Thus threshold values, tissue resistances, and electrogram amplitudes assured a safe pacemaker function. The small diameter and pliable texture of these leads provided a smooth surgical handling. They were found particularly suitable in children. (J THORAC CARDIOVASC SURG 1995;110:1725 31)

Ole-Jörgen Ohm, MD, ${ }^{a}$ Kjell Breivik, MD, ${ }^{a}$ Leidulf Segadal, $M D,{ }^{b}$ and Hogne Engedal, MD, ${ }^{\mathrm{b}}$ Bergen, Norway
Tentente emporary pacing leads are routinely used after cardiac operations. The electrical properties of these leads are important for a safe pacemaker function. We have previously shown that the braided

From Medical Department $A^{a}$ and the Surgical Institute, ${ }^{b}$ University of Bergen, School of Medicine, Haukeland Sykehus, Bergen, Norway.

Received for publication July 31, 1994.

Accepted for publication Jan. 5, 1995.

Address for reprints: Ole-Jörgen Ohm, MD, FACC, Professor of Cardiology, Medical Department A, University of Bergen, School of Medicine, Haukeland Sykehus, N-5021 Bergen, Norway.

Copyright $@ 1995$ by Mosby-Year Book, Inc.

$0022-5223 / 95 \$ 5.00+0 \quad \mathbf{1 2} / \mathbf{1} / \mathbf{6 3 3 3 7}$ multifilament wire electrodes have a high failure rate both for sensing of spontaneous heart activity and safe heart stimulation. ${ }^{1,2}$

The introduction of a temporary lead with a localized fixed surface area was a great improvement that offered superior pacing and sensing performance and minimized chances of dislodgement. ${ }^{3,4}$ Still, commercially available leads have not been found suitable for small children because of a large diameter and poor pliability.

The purpose of the present study was to evaluate the efficacy of two new temporary pacing leads designed specifically for implantation in the atrial and ventricular muscle of the smaller pediatric heart and in the adult to be affixed directly within the 


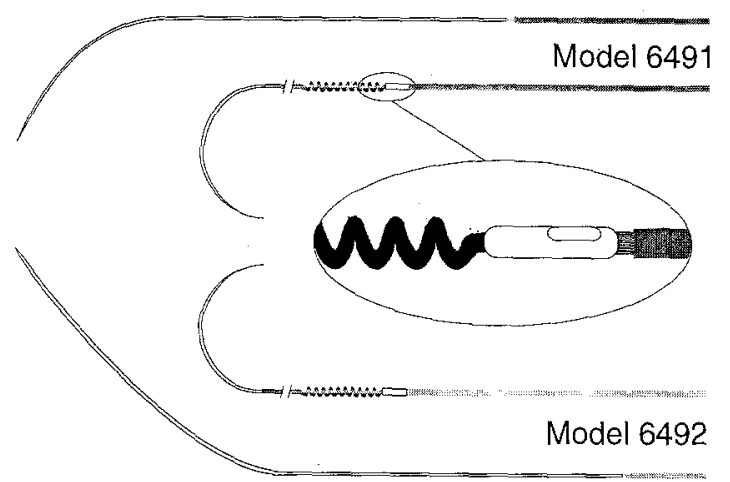

Fig. 1. Pediatric 6491 (top) and adult 6492 (bottom) leads used in study with small distal needle and breakaway chest needle slightly curved distal to breakaway marking. Inset is close-up view of polypropylene fixation coil and discrete electrode (diameter $0.5 \mathrm{~mm}$, surface area $4 \mathrm{~mm}^{2}$ ).

Table I. Congenital heart defects in the 15 children studied

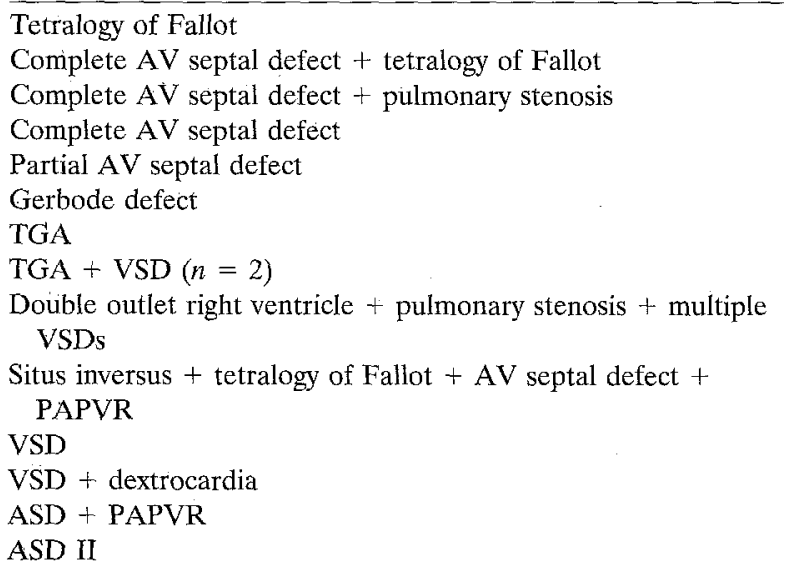

$A V$, Atrioventricular; $T G A$, transposition of the great arteries; VSD, ventricular septal defect; $P A P V R$, partial anomalous pulmonary venous return; $A S D$, atrial septal defect.

atrial myocardium without the need for sutures or special techniques such as use of a silicon disk or atrial plication technique. ${ }^{4,5}$

\section{Patients and methods}

Patients. The patients included in the study were 15 children and 15 adults undergoing cardiac operations. To qualify for the pediatric portion of the study the patients had to weigh $25 \mathrm{~kg}$ or less. They had a variety of congenital heart diseases (Table I). The age range was 3 months to 7 years, and the body weight varied between 4.4 and $20 \mathrm{~kg}$. The 15 adult patients consisted of 14 men and 1 woman aged $59.1 \pm 10.4$ years (range 45 to 78 years). Thirteen pätients underwent coronary bypass grafting ( 7 patients had 3-vessel disease, 6 had 2-vessel disease) and

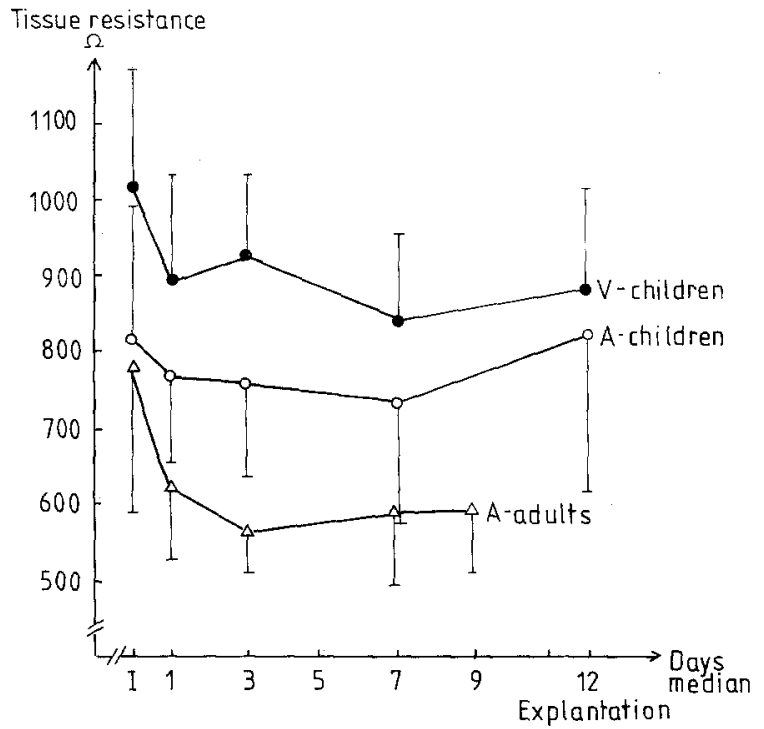

Fig. 2. Tissue resistance calculated from voltage/current ratio $90 \mu \mathrm{sec}$ into pulse at myocardial threshold level using pacing system analyzer (Medtronic 5300). I, Implantation; $V$, ventricle; $A$, atrium.

two underwent aortic valve replacement ( 1 aortic stenosis, 1 combined aortic stenosis and insufficiency).

The study was approved by the regional ethical committee and the patients or parents (for the children) gave written informed consent to participate in the investigation.

\section{Methods}

Leads studied (Fig. 1). The leads used have a small 135-degree (3/8 circle) curved needle with a length of 18 $\mathrm{mm}$ and a diameter of $0.4 \mathrm{~mm}$. A soft 4-0 coiled polypropylene fiber is connected to the distal end of the electrode to serve as a fixation mechanism in the heart. The conductor consists of multifilament stainless steel strands coated with color-coded polyethylene insulation (yellow for pediatric wire [6491] and purple for adult wire [6492]). The diameter measured over the insulation is $0.5 \mathrm{~mm}$. The stainless steel electrode diameter is $0.5 \mathrm{~mm}$ and its surface area is $4 \mathrm{~mm}^{2}$. A stainless steel needle is connected to the proximal end portion of the conductor to bring the conductor wire outside the thorax. The chest needle has a diameter of $0.7 \mathrm{~mm}$ and a length of $60 \mathrm{~mm}$ (pediatric) or $90 \mathrm{~mm}$ (adult). The needle is grooved to enable breakaway of the sharp section and is slightly curved distal to the breakaway marking to ease smooth chest passage. The remaining part functions as a contact sleeve for an electrocardiographic recorder or temporary pulse generator.

Instrumentation. The myocardial excitability threshold, taken at 1 msec pulse width, was measured with a constant voltage source of the condenser discharge type, which also gives the current $90 \mu \mathrm{sec}$ into the pulse (Medtronic 5300 pacing system analyzer, Medtronic, Inc., Minneapolis, Minn.). Thus the initial tissue resistance could be calculated. Additionally, the myocardial threshold was measured with a constant current source (Medtronic 5345 DDD temporary pulse generator). This device also deter- 
Table II. Myocardial excitability thresholds in milliamperes during constant current stimulation at 1 msec pulse width

\begin{tabular}{|c|c|c|c|c|c|}
\hline & Implantation & Day 1 & Day 3 & Day 7 & Explantation * \\
\hline \multicolumn{6}{|l|}{ Atrial, children } \\
\hline Mean $\pm \mathrm{SD}$ & $0.61 \pm 0.34$ & $0.80 \pm 0.50$ & $1.15 \pm 1.18$ & $2.00 \pm 2.65$ & $2.08 \pm 1.86$ \\
\hline Median & 0.5 & 0.65 & 0.8 & 1.0 & 1.5 \\
\hline Range & $0.2-1.4$ & $0.3-1.7$ & $0.2-4.8$ & $0.6-10$ & $0.7-8.0$ \\
\hline \multicolumn{6}{|c|}{ Ventricular, chilldren } \\
\hline Mean $\pm \mathrm{SD}$ & $0.38 \pm 0.13$ & $0.50 \pm 0.20$ & $0.72 \pm 0.38$ & $2.05 \pm 1.75$ & $2.22 \pm 1.63$ \\
\hline Median & 0.3 & 0.4 & 0.6 & 1.2 & 2.0 \\
\hline Range & $0.2-0.7$ & $0.1-1.0$ & $0.4-1.7$ & $0.6-7.0$ & $0.4-7.0$ \\
\hline \multicolumn{6}{|l|}{ Atrial, adults } \\
\hline Mean $\pm \mathrm{SD}$ & $0.95 \pm 1.44$ & $2.25 \pm 2.17$ & $2.00 \pm 1.52$ & $2.84 \pm 1.60$ & $2.76 \pm 2.76$ \\
\hline Median & 0.5 & 1.4 & 1.1 & 2.1 & 2.55 \\
\hline Range & $0.2-6.0$ & $0.4-8.0$ & $0.8-6.0$ & $0.9-6.0$ & $0.9-4.9$ \\
\hline
\end{tabular}

Thresholds measured with Medtronic 5345 DDD temporary pulse generator. $p$ Values $<0.002$ from implantation to explantation. $S D$, Standard deviation. *Median time to lead explant 9 days (range 7 to 13 ) in the adults and 12 days ( 2 to 23 ) in the children.

mines the sensing potentials in millivolts with a lowest value of $0.5 \mathrm{mV}$ and a highest value of $15 \mathrm{mV}$. Myocardial capture was confirmed on an oscilloscope or electrocardiographic recorder, or both. The lead combination that gave the lowest threshold at the initial measurement was connected to the negative terminal of the pulse generator for all subsequent recordings. Myocardial threshold was defined as the lowest voltage or current value that resulted in 1:1 capture when the pulse generator output was gradually increased from below. A dynamometer was used to measure the force in kilograms during lead removal.

Operative procedure. One pair of unipolar leads each was implanted in the interatrial groove or posteriorly in the right atrium and on the nonsystemic ventricle with an approximate spacing of $1 \mathrm{~cm}$ to obtain a bipolar configuration. All leads of each kind were implanted by the same surgeon (L. S. for the children, H. E. for the adults).

Measurements. Measurements were taken at the end of operation or immediately after admission to the intensive care unit, 3 to 6 hours after operation, and thereafter daily through explant.

Statistical methods. Threshold values are given both as mean plus or minus the standard deviation and as median values because of skewed distribution of the data with a few high values. Electrogram amplitudes, initial tissue resistance, and force used during lead removal are given as mean plus or minus the standard deviation. Student's $t$ test was used for comparing the development in myocardial threshold, tissue resistance, and electrogram amplitudes over time. Differencés were considered statistically significant at $p<0.05$.

\section{Results}

Overall, the results were favorable both for cardiac stimulation and sensing of spontaneous heart activity. The leads were used exclusively on the atria of the adult population. Only one male adult patient had an obvious dislocation, which occurred the first postoperative day as evidenced by both sensing failure and exit block. Data for this patient are excluded from further analyses. In four children intermittent sensing failures were observed in the atrial position in the early postoperative phase, and the ventricular leads functioned properly in all cases.

Myocardial threshold at constant current pacing (Table II). With use of the constant current pulse generator, there was a threefold increase in myocardial threshold in the atrial position in children during the observation period, from a mean of 0.61 $\mathrm{mA}$ at implantation to $2.08 \mathrm{~mA}$ at explantation $(p<$ 0.002 ). Although the values at implant were lower in the ventricle (mean $0.38 \mathrm{~mA}$ ), the threshold increased about six times to a mean of $2.22 \mathrm{~mA}$ at explantation, which was also highly statistically significant $(p<0.002)$ and slightly higher compared with values in the atrium. The highest initial threshold values were found in the atrial position in the adults (mean $0.95 \mathrm{~mA}$ ), and also in this group there was a threefold increase during the observation period (mean $2.76 \mathrm{~mA}$ at explantation, $p<$ 0.002 ).

Myocardial threshold at constant voltage (Table III). The current values measured with the constant voltage pulse generator were somewhat higher at implant compared with the values obtained with the constant current source. The reason for this discrepancy is the difference in the output characteristics for the two measuring devices. The increase was, however, of a similar magnitude to that for the constant current pulse generator during the observation period. Mean atrial current values in the infants increased from $0.88 \mathrm{~mA}$ to $3.24 \mathrm{~mA}$ and ventricular current values from $0.63 \mathrm{~mA}$ at implantation to $3.1 \mathrm{~mA}$ at explantation. Corresponding values in the atrium in the adults were $1.52 \mathrm{~mA}$ and 
Table III. Myocardial excitability thresholds during constant voltage stimulation at 1 msec pulse width

\begin{tabular}{|c|c|c|c|c|c|c|c|c|c|c|}
\hline & \multicolumn{2}{|c|}{ Implantation } & \multicolumn{2}{|c|}{ Day 1} & \multicolumn{2}{|c|}{ Day 3} & \multicolumn{2}{|c|}{ Day 7} & \multicolumn{2}{|c|}{ Explantation } \\
\hline & $V$ & $m A$ & $V$ & $m A$ & $V$ & $m A$ & $V$ & $m A$ & $V$ & $m A$ \\
\hline \multicolumn{11}{|l|}{$\begin{array}{l}\text { Atrial leads, } \\
\text { children }\end{array}$} \\
\hline Mean $\pm S D$ & $0.70 \pm 0.30$ & $0.88 \pm 0.35$ & $1.14 \pm 0.55$ & $1.56 \pm 0.91$ & $1.29 \pm 1.18$ & $1.93 \pm 2.34$ & $1.8 \pm 1.56$ & $3.21 \pm 3.99$ & $2.37 \pm 1.24$ & $3.24 \pm 2.91$ \\
\hline Median & 0.6 & 0.85 & 1.2 & 1.4 & 0.95 & 1.05 & 1.25 & 1.9 & 2.35 & 2.2 \\
\hline Range & $0.3-1.3$ & $0.5 \cdot 1.5$ & $0.4-2.0$ & $0.6-3.4$ & $0.45-4.1$ & $0.6-7.6$ & $0.7-5.5$ & $1.1-13.7$ & $0.85-5.2$ & $1.1-11.2$ \\
\hline \multicolumn{11}{|l|}{$\begin{array}{l}\text { Ventricular } \\
\text { leads, } \\
\text { children }\end{array}$} \\
\hline Mean $\pm \mathrm{SD}$ & $0.63 \pm 0.20$ & $0.63 \pm 0.22$ & $0.66 \pm 0.25$ & $0.73 \pm 0.7$ & $1.05 \pm 0.48$ & $1.17 \pm 0.6$ & $2.29 \pm 1.2$ & $2.92 \pm 1.95$ & $2.52 \pm 1.21$ & $3.1 \pm 1.89$ \\
\hline Median & 0.6 & 0.65 & 0.7 & 0.6 & 0.85 & 1.1 & 2.2 & 1.9 & 2.55 & 2.75 \\
\hline Range & $0.35-1.0$ & $0.4-1.1$ & $0.2-1.05$ & $0.3-1.2$ & $0.6-2.25$ & $0.6-2.5$ & $1.35-5$ & $1.5-7.6$ & $0.6-3.6$ & $0.6-7.45$ \\
\hline \multicolumn{11}{|l|}{$\begin{array}{l}\text { Atrial leads, } \\
\text { adults }\end{array}$} \\
\hline Mean $\pm \mathrm{SD}$ & $1.06 \pm 1.08$ & $1.52 \pm 2.19$ & $2.18 \pm 1.53$ & $4.01 \pm 3.33$ & $2.04 \pm 1.32$ & $3.60 \pm 2.13$ & $2.7 \pm 1.35$ & $4.71 \pm 2.47$ & $2.76 \pm 1.42$ & $4.67 \pm 2.52$ \\
\hline Median & 0.85 & 0.8 & 1.8 & 2.95 & 1.5 & 2.6 & 2.2 & 4.75 & 2.4 & 4.3 \\
\hline Range & $0.25-4.5$ & $0.4-9.0$ & $0.55-4.7$ & $0.8-12.0$ & $0.9-5.5$ & $1.5-8.6$ & $1.0-5.0$ & $1.6-9.3$ & $0.9-4.65$ & $1.6-8.75$ \\
\hline
\end{tabular}

Thresholds measured with Medtronic 5300 pacing system analyzer. $p$ Values $<0.002$ from implantation to explantation. $S D$, Standard deviation.

Table IV. Electrogram amplitudes

\begin{tabular}{lccc}
\hline & $\begin{array}{c}\text { Atrial, children } \\
(\mathrm{mV})\end{array}$ & $\begin{array}{c}\text { Ventricular, } \\
\text { children }(\mathrm{mV})\end{array}$ & $\begin{array}{c}\text { Atrial, } \\
\text { adults }(\mathrm{mV})\end{array}$ \\
\hline Implantation & $1.8 \pm 1.5$ & $13.1 \pm 3.0$ & $2.0 \pm 1.3$ \\
& $(0.5-6)$ & $(6-\geq 15)$ & $(0.5-6)$ \\
Day 1 & $1.8 \pm 1.7$ & $12.1 \pm 4.7$ & $1.8 \pm 2.1$ \\
& $(\leq 0.5-7)$ & $(12.5-\geq 15)$ & $(0.5-8)$ \\
Day 3 & $2.1 \pm 1.9$ & $11.3 \pm 4.5$ & $2.2 \pm 1.7$ \\
& $(\leq 0.5-7)$ & $(2-\geq 15)$ & $(\leq 0.5-6)$ \\
Day 7 & $1.6 \pm 1.2$ & $9.5 \pm 4.7$ & $1.8 \pm 1.1$ \\
& $(\leq 0.5-5)$ & $(3-15)$ & $(0.5-4)$ \\
Explantation & $1.6 \pm 1.2$ & $8.7 \pm 4.5$ & $1.8 \pm 1.1$ \\
& $(\leq 0.5-4)$ & $(3-\geq 15)$ & $(0.5-4)$
\end{tabular}

Electrograms measured with Medtronic 5345 DDD temporary pulse generator. Values given as mean plus or minus the standard deviation with the range given in parentheses.

$4.67 \mathrm{~mA}$. The voltage threshold showed a threefold to fourfold increase during the study period. In the children the atrial threshold increased from a mean value of $0.70 \mathrm{~V}$ to $2.37 \mathrm{~V}$ and the threshold in the ventricle increased from $0.63 \mathrm{~V}$ at implantation to $2.52 \mathrm{~V}$ at explantation. Corresponding values in the atrial position in the adults were $1.06 \mathrm{~V}$ and $2.76 \mathrm{~V}$ (all $p$ values $<0.002$ ).

Initial tissue resistance (Fig. 2). Included in the tissue resistance is also the resistance of the lead wire, which is $16 \Omega$. Because the leads were applied in the bipolar fashion, the wire resistance equals 32 $\Omega$ and thus represents a minor portion of the total resistance. The atrial tissue resistance was almost equal in children and in adults at implant. During the observation period there was a more marked and statistically significant drop in tissue resistance in the adults $(p<0.004)$ to a level of about $150 \Omega$ lower than that in the children and the value showed little variation after this initial drop through the study period.

Initially the tissue resistance was about $200 \Omega$ higher in the ventricle than in the atrium and it demonstrated a marked and statistically significant drop during the observation period $(p<0.05)$. Throughout the study the tissue resistances were about $100 \Omega$ higher in the ventricle than in the atrium for the children.

Electrogram characteristics (Table IV and Fig. 3 ). The atrial electrograms were of similar amplitude in the children and adults and showed little change in mean values over time ( $p=$ not significant). The ventricular electrograms showed a continuous and statistically significant drop through the observation period $(p<0.005)$.

In Fig. 3 an example is given of the use of the atrial leads both for diagnosis and treatment of an arrhythmia during the postoperative phase in one of the children with complex congenital heart disease.

Removal of leads. At explant a dynamometer was used to measure the kilograms of force applied during removal of the leads. Because each pair of leads was tied together, they were removed simultaneously. The extraction force in the atrium varied between 0.08 and $0.83 \mathrm{~kg}(0.35 \pm 0.18 \mathrm{~kg}$, children $)$ and 0.08 and $0.60 \mathrm{~kg}(0.34 \pm 0.13 \mathrm{~kg}$, adults $)$. In the ventricle the force varied from 0.08 to $0.51 \mathrm{~kg}(0.26 \pm$ $0.12 \mathrm{~kg}$ ). 


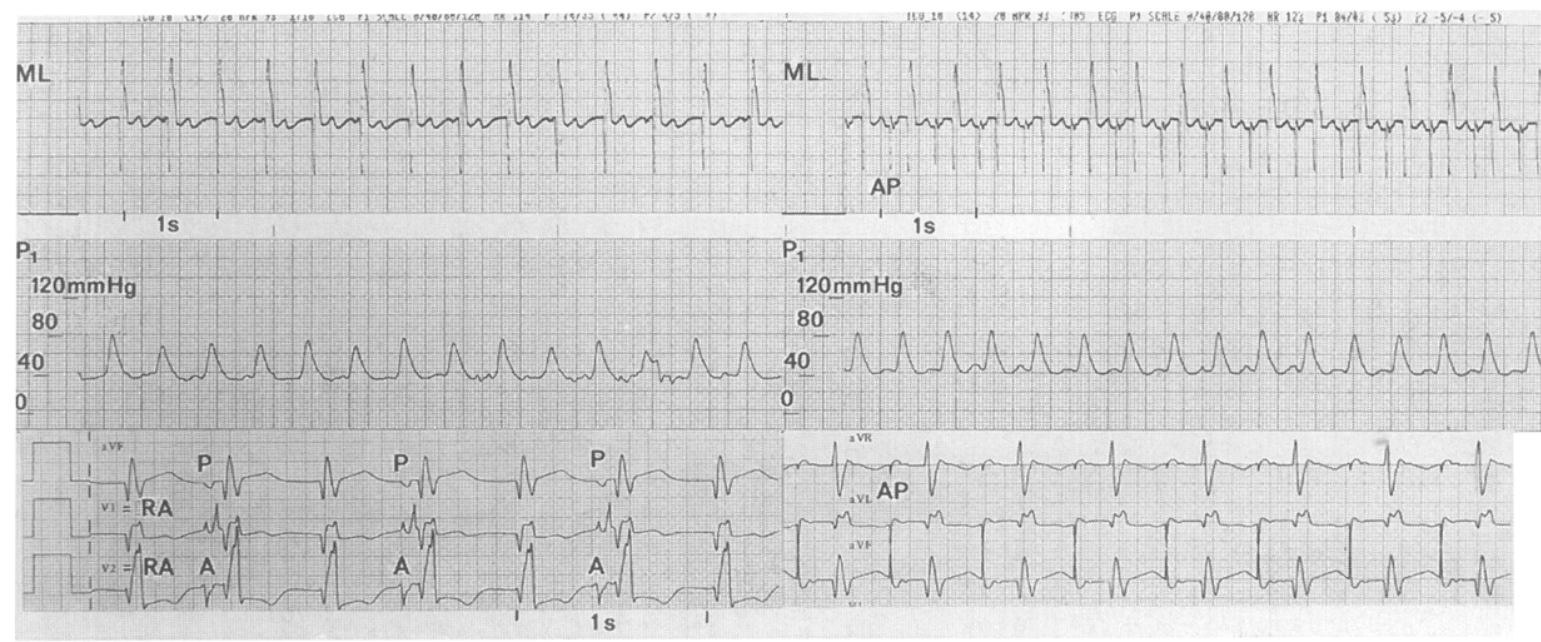

Fig. 3. Electrocardiographic and invasive blood pressure recordings on postoperative day 6 from 2-year"old girl operated on because of situs inversus, tetralogy of Fallot, atrioventricular septal defect, and partial anomalous pulmonary venous return. During postoperative phase heart rhythm changed between sinus rhythm and accelerated atrioventricular $(A V)$ junctional rhythm. Recording directly from atrial leads $(R A)$ demonstrated atrial rhythm at rate of 60 beats $/ \mathrm{min}$ and accelerated $\mathrm{AV}$ junctional rhythm at rate of 120 beats/min (left part of figure). This is not obvious from monitoring lead $(M L)$. In this case $1: 1 \mathrm{AV}$ conduction was obtained with atrial pacing (right part of figure). Atrial pacing $(A P)$ close to spontaneous rate resulted in marked blood pressure elevation $(P 1)$ and general improvement in patient's clinical condition.

\section{Discussion}

The primary goal of this study was to investigate the handling and mechanical and electrical properties of these new leads. Both in the atrium and ventricle adequate sensing and secure pacing could be obtained. With the exception of a $30 \mathrm{~mm}$ longer chest needle for the adults and color coding of the leads, the characteristics of the pediatric and adult versions of the leads are similar.

Handling and mechanical properties. The handling properties of the leads were advantageous. The maximal diameter of $0.5 \mathrm{~mm}$ of the lead, introduced with an even thinner distal needle, assured minimal trauma when the electrode was placed within the myocardial wall. No bleeding or dislocation was observed immediately after placement of the leads. This has been of special concern in infants and with thin atrial walls in adults. In some earlier models a silicon rubber disk has been recommended for the fixation of similar leads to the epicardium. ${ }^{4,5}$ With the present models no additional fixation mechanism had to be used except for the retaining coil fastened to the distal end of the electrode. Obviously this coil did not result in additional damage to the tissue. Furthermore, the low force that had to be used during removal indicates a good balance in the memory of the retaining coil. A similar but somewhat higher extraction force had to be used when removing the leads from the atrium, both in children and adults, compared with the force required to remove the leads from the ventricles of the children. There was no indication of bleeding after lead removal. Although it has not been tested in this study, it is expected that the lead will function favorably also in the ventricle in the adult inasmuch as the electrode geometry and fixation mechanism are identical for the pediatric and adult lead versions.

Myocardial threshold. In none of the patients was there indication of wire breakage or insulation defects after a maximal observation period of 23 days. Compared with those in earlier studies these new leads showed similar values of myocardial thresholds for temporary heart wires with a controlled surface area. ${ }^{4-7}$ Also, the myocardial threshold values showed little difference in the atrial and ventricular positions. Although there was a continuous increase in myocardial threshold values, the values were low with a high safety margin for pacing (20 $\mathrm{mA}$ for the constant current pulse generator, 10 $\mathrm{V}$ for the constant voltage pulse generator). There was somewhat higher atrial threshold values in the 
adult than in the pediatric hearts, which can possibly be explained by structural changes in the myocardium caused by long-standing heart disease or less direct contact with excitable myocardial tissue as a result of more fatty tissue in the interatrial groove.

Tissue resistance. The tissue resistance was of similar magnitude to that found for permanent pacemaker leads with a comparable surface area ${ }^{8}$ and on average 200 to $300 \Omega$ higher than that found for earlier temporary electrode models with a localized stainless steel electrode with a surface area of $7.5 \mathrm{~mm}^{2} .^{3,4}$ This is of great importance to obtain an adequate current waveform during heart stimulation and thus secure optimal pacemaker function. This will furthermore decrease the current drain on the pulse generator, although this latter factor is of lesser importance in a temporary system. Also, the stable tissue resistance values throughout the study period indicated the integrity of the leads. There is no obvious explanation for the more marked drop and lower tissue resistance in the adults, because the electrodes are identical. Of note also is the higher tissue resistance found in the ventricular myocardium compared with that in the atrial myocardium.

Electrogram amplitudes. Atrial electrogram amplitudes were of similar size to those found for earlier models of temporary pacing leads in which different application techniques had been used..$^{3-5}$ In four children the atrial electrograms intermittently showed borderline amplitudes for adequate sensing $(\leq 0.5 \mathrm{mV})$ with the pulse generator used. In two or three of these cases this could be ascribed to temporary instability in the childrens' clinical condition. The ventricular electrogram findings were comparable to values found for permanent and temporary pacemaker leads. ${ }^{3,9}$ In the ventricle there was a high sensitivity margin although there was a continuous drop in amplitude during the observation period.

Applicability of the leads. Heart wires can effectively be used for diagnosis and treatment of cardiac arrhythmias in the postoperative phase of cardiac operations. Not only can pacing be used in case of bradyarrhythmia to improve the hemodynamic situation, but also by use of these wires episodes of supraventricular and ventricular tachycardias can be treated immediately without additional invasive procedures. Furthermore, antiarrhythmic drugs with negative inotropic and potential proarrhythmic effects and direct cardioversion necessitating the use of general anesthesia can be avoided. These wires can also be used for electrophysiologic testing before hospital discharge: for example, in patients who have had surgery for ventricular tachycardia.

Recognition of atrioventricular synchrony. With the now available external DDD pacemaker it is important to have a reliable atrial lead to take advantage of improved hemodynamics of atrioventricular synchrony, especially for the patient with poor left ventricular function, reduced compliance, or complex congenital heart corrections (Fig. 3). Because the leads are applied in the bipolar fashion a high pulse generator sensitivity can be used with little risk for oversensing or cross-talk between the atrial and ventricular channels. Furthermore, interference from external sources seems unlikely.

Conclusion. The new temporary pacing leads have shown good performance in patients undergoing cardiac operations. Because of the slender construction and pliable texture of the leads trauma to the heart is minimal. The special memory coil secures safe positioning without additional fixation mechanisms. The leads seem particularly favorable for application in small children and for atrial application in the adult.

The support of Mr. Wim van Driel, Manager Heart Valve Department, Bakken Research Center, Maastricht, The Netherlands, is highly appreciated.

\section{REFERENCES}

1. Ohm O-J, Mörkrid L, Skagseth E. Temporary pacemaker treatment in open heart surgery: variation in myocardial threshold, tissue and interface impedances in man. PACE 1979;2:162-74.

2. Ohm O-J, Skagseth E. Temporary pacemaker treatment in open heart surgery: pre- to postoperative changes in the electrogram characteristics. PACE 1980; 3:150-8.

3. Breivik K, Engedal H, Segadal L, Ohm O-J. New temporary pacing lead for use after cardiac operations. J THORAC Cardiovasc SuRg 1982;84:787-94.

4. Breivik K, Engedal H, Resch F, Segadal L, Ohm O-J, Bipolar atrial application of a new temporary pacing lead after cardiac operations. J THORAC CARDIOvasC SURG 1983;85:625-31.

5. Ferguson TB, Cox JL. Temporary external DDD pacing after cardiac operations. Ann Thorac Surg 1991;51: 723-32.

6. Wigneswaran WT, Jamieson MPG. Temporary pacing leads in cardiac surgery: a comparison of multifilament braided electrode and localized solitary stainless steel electrode. J Cardiovase Surg 1986;27: 609-12. 
Volume 110, Number 6

7. Wirtz St, Schulte HD, Winter J, Godehardt E, Kunert J. Reliability of different temporary myocardial pacing leads. Thorac Cardiovasc Surg 1989;37:163-8.

8. Hoff PI, Breivik K, Tronstad A, Andersen KS, Ohm O-J. A new steroid-eluting electrode for low-threshold pacing. In: Pérez Gómez F, ed. Cardiac pacing, electrophysiology, tachyarrhythmias. Mount Kisco, New York: Futura Media Services, 1985:1014-9.

9. Ohm O-J, Breivik K, Hammer EA, Hoff PI. Intraoperative electrical measurements during pacemaker implantation. Clin Prog Pacing Electrophysiol 1984;2:123. 